\title{
Lost gold: the decline of the academic mission in US medical schools
}

\begin{abstract}
Medical education needs to be redesigned so that it is an equally shared responsibility of clinicians and physician-scientists, with greatly enhanced opportunities for student-faculty bonding. Traditional departments and divisions must be restructured to provide more thoughtful and effective support for academic clinicians and physician-scientists. Existing infrastructure should be improved so that in exchange for the commitment of time and effort for teaching, the faculty members receive tangible services from their institutions (e.g., information technology that actually saves time, stateof-the art teaching aids that are user friendly, streamlined administrative oversight to avoid duplicate submissions to regulatory offices, more helpful grant management and accounting).
\end{abstract}

At the dawn of the twentieth century, physicians were trained in much the same way as other skilled laborers, such as blacksmiths or stonemasons. Trainees were apprenticed to experienced doctors to learn how to diagnose and treat human illnesses. All that changed in 1910 with the publication of the Flexner Report. Commissioned by the Carnegie Foundation, Abraham Flexner's report, entitled "Medical Education in the United States and Canada," codified the training and licensing of physicians. Training physicians became the purview only of professors of medicine at accredited academic institutions, many of whom pursued scientific research in addition to patient care and teaching. As a result, the value of the inquisitive mind was officially recognized, and the most exciting seventyfive years of biomedical discovery ensued.

Now it seems that this powerful engine of discovery is being derailed at an alarming rate. At the earliest stages of physician-scientist career development, real and perceived pressures from an overloaded, inefficient, and economically stressed health care delivery system are driving house staff, fellows, and attending physicians away from the academic model of physician training.

Many of us who were trained during the "golden age" of American medical education (roughly 1950-1990) remember with fondness and longing the incredibly stimulating and challenging academic rounds on hospital wards. The excitement of the quest for a diagnosis and an effective therapy together with the prospect of working with a wise, well-read, and professorial attending physician was usually sufficiently engaging to hold the attention of even the most sleep-deprived house officer. As we progressed through postgraduate education, many of us spent several or more years in basic science laboratories, learning and conducting research that would help to change the context of the practice of medicine. Driving this vibrant intellectual venture were visionary academic leaders who recognized, valued, and supported the biomedical research and the faculty at their medical schools. Of course, the $\mathrm{NIH}$, charitable organizations, and foundations also played major roles in supporting the academic mission of US medical schools, contributing to the creation of a productive, dynamic biomedical research infrastructure that was the envy of the world.

Medical students were constantly exposed to the seductive opportunities of the world of biomedical research. They could expect to know and be taught by professors whose research was uncovering startling new truths about the living universe. The opportunity to participate in the art of discovery, combined with the privilege of caring for patients and delivering the latest advanced diagnostics and therapeutics, was attracting the best and the brightest to train in US medical schools. However, the forces that initiated the quest for knowledge and discovery gradually became the architects of its destruction.

At the beginning of the golden era, a few brilliant physician-scientists at each of the major medical schools were highly valued by their colleagues for their intellectual power and research, and their work contributed to advances in patient care. As the focus of biomedical research became increasingly specialized, and less clinical, scientists and clinicians became increasingly polarized. Today it seems they hardly know one another. The causes of this polarization include competition for limited resources; lack of familiarity with each other; misguided and overwhelming emphasis on extreme models (e.g., each faculty member has to have 3 independent NIH grants or generate a set number of billing units); and an archaic departmental structure that fails to value interactions between physicians and scientists.

Indeed, the very best hope for advancing health care through basic, translational, and clinical research is being lost. Scientists rarely interact with clinicians, so it is difficult for them to ascertain the nuances and complexities of the diseases they are investigating. Further damaging is the degree to which the physician-scientists have been eliminated from the training of medical students. Medical rounds are losing their academic quality, as harried house officers wilt under the weight of double-digit nightly admissions. The focus of academic medical centers is changing from patient care/teaching/research to length-of-stay/ product lines/marketing.

Can we recover the lost promise of the golden era, or is it too late? The answer lies in the lessons of the past. A new generation of visionary leaders with the courage to tackle difficult problems is needed to refashion the enterprise of medical education and reshape the structure of academic health centers. Given that each institution has its own issues, the road to redemption will depend on local circumstances, but if we continue on the present course, it is unlikely anyone will try to resurrect the academic aspect of our health centers, and they will cease to be academic.

Reshaping the academic mission of medical schools can be accomplished with current technology and resources but will require leaders who are willing to disrupt the status quo and invest in change for future benefit. These actions require vision and courage, because the benefits of change are difficult to measure during the relatively short tenure of the typical medical school dean or health center CEO. Our leaders must rise above the masses, look the financial officers and trustees straight in the eye, and declare the primacy of the academic mission in US medical schools.

\section{Andrew R. Marks Editor-in-chief}

